\title{
Trilha da Vida Silvestre: um jogo a partir do monitoramento de atropelamento de animais em trecho da Rodovia MS-162
}

\section{Track Wild Life: a game from animal trampling monitoring in stretch of Highway MS-162}

Pista de Vida Salvaje: un juego de seguimiento de animales en pisoteo tramo de la Carretera MS-162

Maria Jéssica Pereira Viturino ${ }^{1}$ Suelen Regina Patriarcha Graciolli²

${ }^{1}$ Formada em Ciências Biológicas pela Universidade Católica Dom Bosco (UCDB), Especialista em Educação Ambiental em Espaços Educadores Sustentáveis (UFMS). E-mail: kjjpereira@hotmail.com

${ }^{2}$ Graduada em Ciências Biológicas pela Universidade Federal de Mato Grosso do Sul (bacharelado e licenciatura). Especialista em Educação Ambiental (SENAC), Mestre em Ensino de Ciências (UFMS). E-mail: suelenpatriarcha@yahoo.com.br 
Resumo: O atropelamento de animais silvestres é um fator recorrente causando danos às espécies atropeladas e às demais, pois altera toda uma dinâmica natural. 0 atropelamento de animais silvestres está hoje entre as causas de maior perda de biodiversidade, fazendo-se necessário que o assunto seja abordado nos diversos grupos, desde condutores de veículos até as crianças nas escolas e comunidade geral, visando amenizar esses impactos. Nesse sentido, objetivou-se neste trabalho monitorar a fauna atropelada em trecho da MS-162, que liga Sidrolândia, MS, ao Distrito Quebra Coco, na perspectiva de ferramenta para educação ambiental, visando à produção de um material didático. A pesquisa foi realizada durante cinco meses, sendo monitoramento quinzenal, tendo como resultado a ocorrência de 18 animais atropelados. Dentre eles, encontraram-se nove espécies diferentes, com dominância de atropelamento de tamanduás. Após pesquisa e obtenção dos dados elaborou-se um jogo didático, intitulado "Trilha da Vida Silvestre".

Palavras-chave: biodiversidade; estradas; jogo didático.

Abstract: The trampling of wild animals is a recurrent factor causing damage to trampled and others species, because amends a whole natural dynamics. The trampling of wild animals is today among the causes of greater loss of biodiversity, making it necessary for the matter to be approached in various groups, since drivers of vehicles until children in schools and community general, aiming to minimize these impacts. In this sense, the objective of this study was to monitor the trampled fauna in passage from the MS-162, which connects Sidrolândia, MS, to the Quebra Coco District, in the perspective of tool for environmental education, aiming at the production of a didactic material. The research was carried out for five months, and biweekly monitoring, having as a result the occurrence of 18 animals get hit. Among them, nine different species were found, with a dominance of trampling of anteaters. After searching and obtaining the data, a didactic game was created, titled "Wildlife Trail".

Key words: biodiversity; roads; didactic game.

Resumen: Pisoteo de animales salvajes es un factor recurrente en el período previo al día durante causar daños a las especies y otras especies, por tanto, cambia todas las dinámicas naturales. pisoteo animal salvaje es hoy en día una de las causas de la pérdida adicional de la biodiversidad, por lo que es necesario que el asunto se aborda en los diferentes grupos, desde los conductores de vehículos a los niños de la escuela y la comunidad en general, con el objetivo de mitigar estos impactos. En este sentido, este trabajo tuvo como objetivo monitorear la fauna atropellados MS estiramiento-162, que conecta Sidrolândia, MS, para las vacaciones de Distrito Coco, desde la perspectiva de una herramienta para la educación ambiental, dirigido a la producción de material educativo. La encuesta se realizó durante cinco meses, a través del seguimiento quincenal, lo que resulta en la aparición de 18 alydinotte. Entre los individuos consigo golpe cumplido nueve especies diferentes, con el predominio de pisoteo de los osos hormigueros. Con la investigación y recopilación de datos elaborado un juego educativo pista desde la perspectiva de una herramienta para la educación ambiental.

Palabras clave: la biodiversidad; carreteras; juego educativo. 


\section{INTRODUÇÃO}

O atropelamento de animais silvestres na MS-162, no trecho Quebra Coco/Sidrolândia, MS, vem ocorrendo com frequência e, em grande parte dos casos, os animais vêm a óbito. Nem sempre as pessoas têm consciência do grande dano causado às espécies e ao ambiente na ocorrência de atropelamento em rodovias. Cabe ressaltar que a morte de espécies animais altera toda uma cadeia que se interliga através de relações ecológicas. Na busca de soluções para resolverem os dados apontados, a educação continua sendo a melhor maneira de mudar essa realidade.

O presente trabalho pretende colaborar com professores e alunos na defesa e conservação da fauna local, que, através do atropelamento envolvendo o homem e o animal silvestre, está sendo prejudicada. Nesse sentido, objetivou-se neste trabalho monitorar a fauna atropelada em trecho da MS-162 que liga o Distrito Quebra Coco à Sidrolândia, MS, na perspectiva de uma ferramenta para educação ambiental, visando à produção de um material didático para estudantes do Ensino Fundamental.

\section{METODOLOGIA}

\subsection{Monitoramento dos atropelamentos na BR 162 trecho Quebra Coco/Sidrolândia, Mato Grosso do Sul e perfil da paisagem do entorno da área}

O monitoramento de atropelamentos foi realizado na Rodovia MS 162, trecho Quebra Coco/Sidrolândia, MS, perfazendo $31 \mathrm{Km}$. Iniciou-se o estudo das características da área amostral, sua composição, fragmentos, áreas de pastagem, plantações etc. Para a análise da paisagem da área amostral, percorreu-se o trajeto realizando o registro, a cada quilômetro, da composição que havia no entorno 
da rodovia, sendo considerada apenas a composição às margens da rodovia.

Com a obtenção dos dados sobre o perfil da paisagem, iniciou-se o monitoramento dos atropelamentos. Para isso, o trecho da BR 162 escolhido para a realização da pesquisa foi percorrido a cada quinze dias, sendo que poderia ocorrer a diferença de um dia para mais ou para menos para a realização do monitoramento. O monitoramento ocorreu durante período de cinco meses, compreendido de novembro de 2013 a março de 2014. Para percorrer o trajeto, a velocidade estabelecida foi de $60 \mathrm{Km} / \mathrm{h}$. O monitoramento consistia em observar e amostrar os dados durante a ida e a vinda do trajeto.

Cada animal atropelado encontrado era registrado em planiIha e fotografado. Na planilha, realizava-se o registro das seguintes informações: número da amostra, data, local de amostragem (Km), característica do local (características de composição da área), nome popular/vulgar e nome científico. A identificação do Km dava-se de acordo com a quilometragem do veículo ou até mesmo pela sinalização viária. Após o período de pesquisa de campo e obtenção dos dados, produziu-se o jogo didático de trilha com base nos resultados da pesquisa.

\subsection{Jogo didático: Trilha da Vida Silvestre}

Depois da realização da pesquisa/monitoramento do trecho da BR 162 que liga o Distrito de Quebra Coco à Sidrolândia, compreendendo os km de 50 a 80, produziu-se o jogo didático "Trilha da Vida Silvestre".

O jogo elaborado foi fiel às informações obtidas durante a pesquisa de campo. O jogo só não relata o atropelamento do furão Galictis vittata, devido a este ter sido identificado posteriormente; a princípio o animal foi considerado um filhote de tamanduá, isso se 
deve ao fato de a identificação ter sido feita apenas a partir de imagens, já que não se tinha licença do IBAMA para manejo e coleta do animal. A arte elaborada representa o trecho da BR 162, Km 50 a Km 80. No tabuleiro do jogo (Figura 1), ao longo da trilha, encontram-se as paisagens ao longo do trecho pesquisado, bem como os atropelamentos encontrados durante o monitoramento.

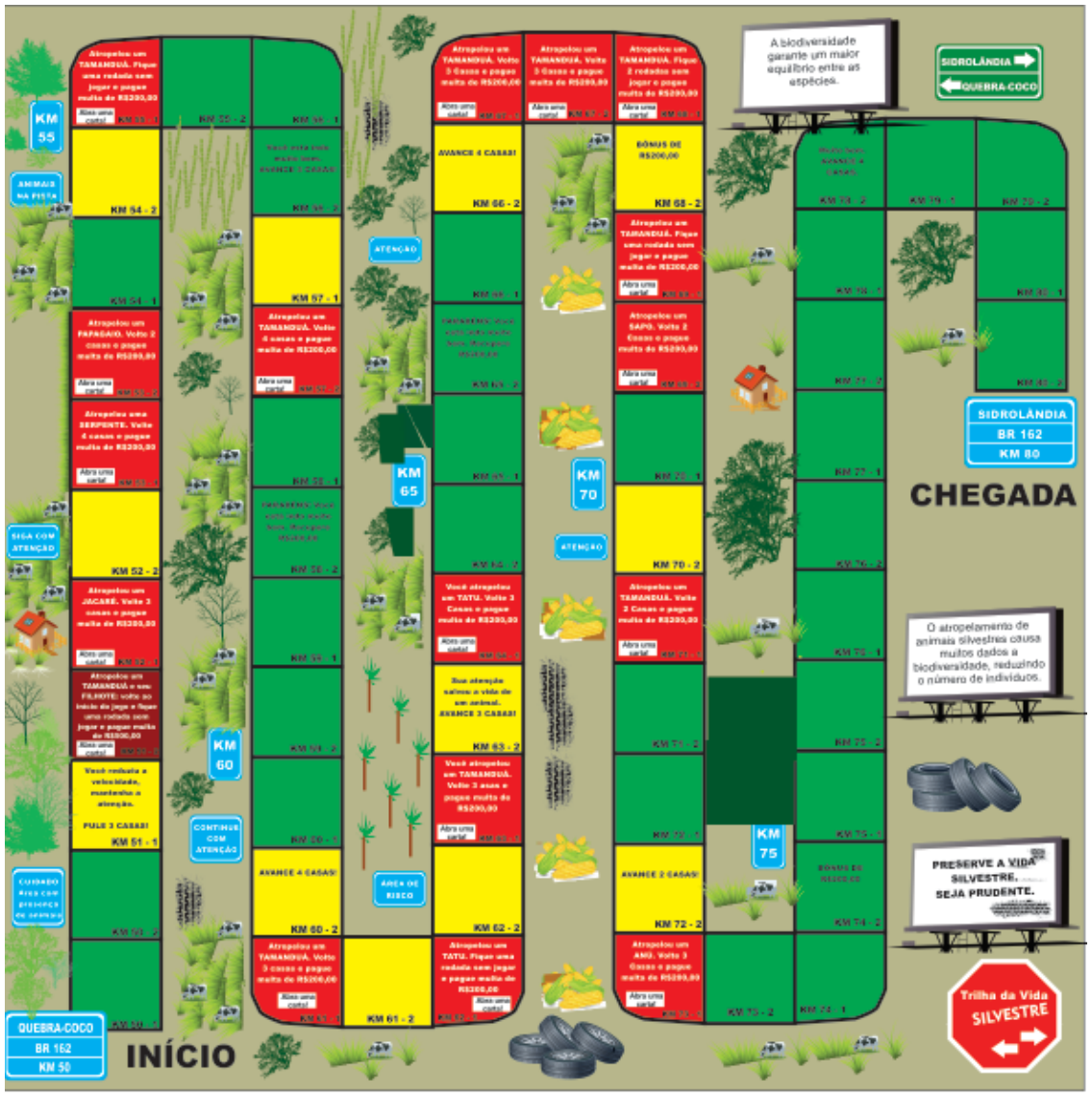

Figura 1- Tabuleiro do Jogo "Trilha da Vida Silvestre" 
O jogo de trilha produzido pode ser jogado por dois até seis jogadores numa mesma partida. Cada participante terá uma peça que o representará e iniciará o jogo com uma quantia de $\mathrm{R} \$ 2.000,00$ reais cada um, isso em notas de dinheiro (Figura 2) elaboradas pelos autores e que fazem parte da "Trilha dos Animais Silvestres". A trilha é composta por 62 "quadrados" que correspondem aos 31 km monitorados, sendo cada quilômetro representado por duas casas, isso se deve ao fato de terem ocorrido quilômetros com o registro de mais de um animal atropelado. Dentro de cada casa há a numeração do quilômetro e a cada 5 quilômetros há uma placa indicativa de quilometragem também.

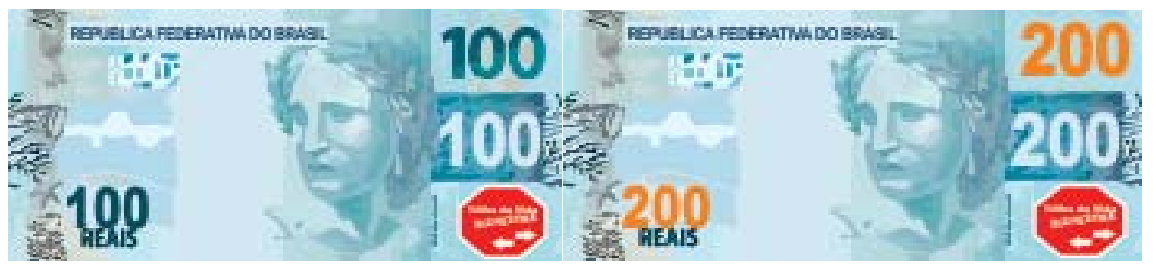

Figura 2- Notas de dinheiro elaboradas para o Jogo "Trilha da Vida Silvestre"

A trilha é contornada de cor preta, e as casas - os Km-foram coloridas pelas cores vermelho, amarelo e verde. As casas na cor vermelha são aquelas em que houve a presença de animal atropelado, ocorrendo um destaque para casos de duplo atropelamento, nos quais o tom de vermelho fica mais escuro. As casas amarelas são aquelas que antecedem a um atropelamento, servindo de alerta para o jogador, e as demais casas são de coloração verde, indicando que pode percorrer a área com tranquilidade. A ilustração com essas cores faz alusão às cores dos semáforos, que são comumente conhecidas e que a criança já tem conhecimento do que cada uma indica, além de tornar o jogo mais próximo com uma via de trânsito. 
Dentro das casas, há informações, bônus e penalidades que o jogador deve seguir. Durante o percurso, o jogador deverá ler algumas cartas que estão espalhadas pela pista. As cartas contêm informações dos animais atropelados com o objetivo de proporcionar ao jogador conhecimento a respeito da ecologia do animal, sendo três cartas para cada indivíduo atropelado, estimando que mais de um jogador pode passar pela mesma casa e, por isso, é importante que tenham informações diferentes. Com essa estimativa, cogita-se a possibilidade máxima de $50 \%$ dos jogadores atropelarem o mesmo animal, caso isso venha a ocorrer.

Ao atropelar um animal, o jogador deve abrir e ler em voz alta uma carta (Figura 3) sobre o animal atropelado. Durante o percurso do jogo, existem multas em valores financeiros, fazendo alusão às multas ambientais, com isso o jogador terá que pagá-las com o dinheiro inicial recebido; Vence aquele jogador que chegar ao final da trilha com uma quantia de pelo menos $\mathrm{R} \$ 1.000,00$ ( mil Reais). Caso o jogador chegue à casa de chegada, mas não tenha a quantia necessária será eliminado, e o jogo continua até que um dos jogadores alcance o mesmo local com o valor exigido. 


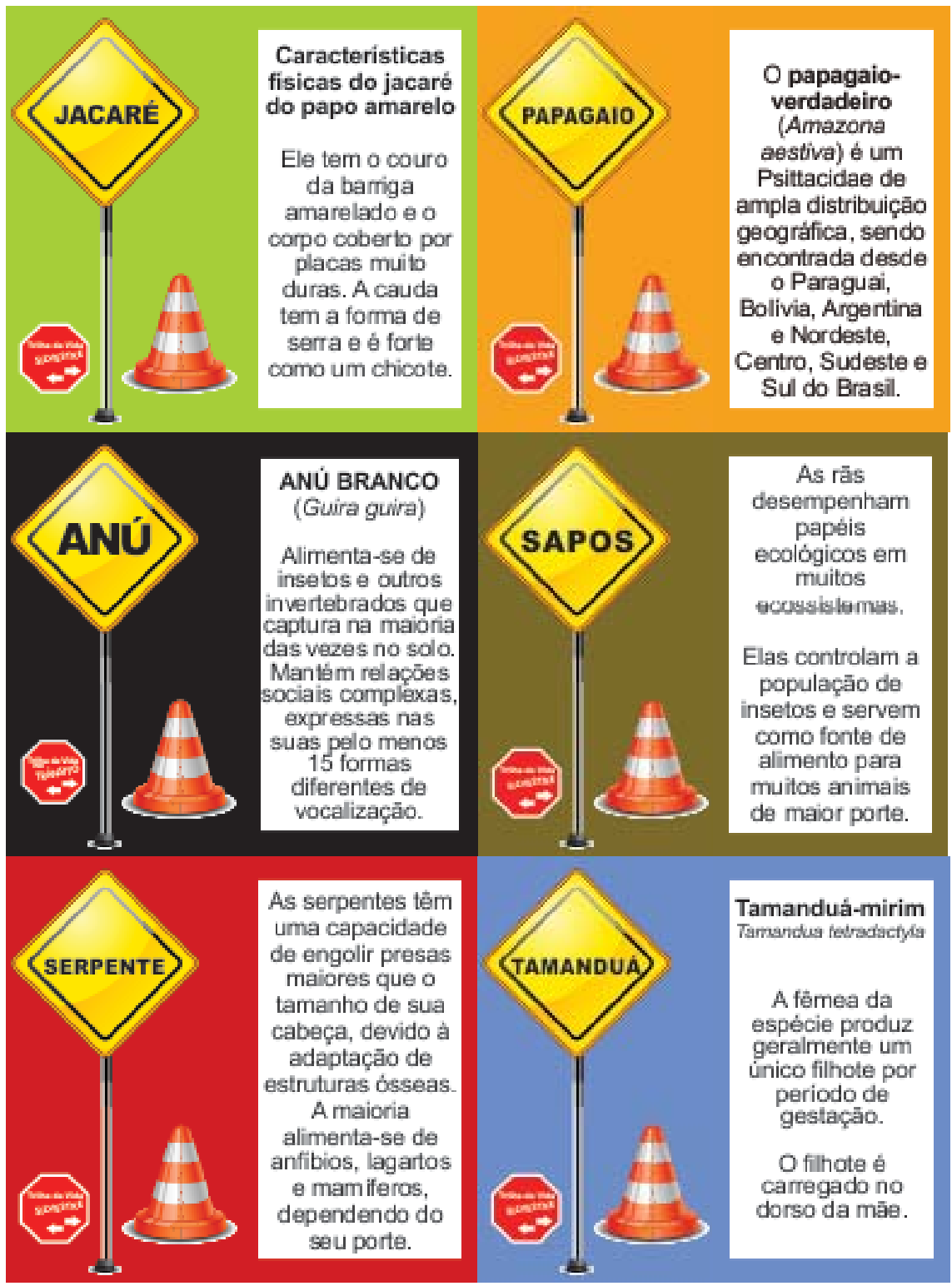

Figura 3- Exemplos das cartas (frente e verso) sobre os animais encontrados atropelados 


\section{RESULTADOS}

\subsection{Resultados da pesquisa de monitoramento dos atropelamentos na BR 162, trecho Quebra Coco/Sidrolândia, Mato Grosso do Sul e perfil da paisagem do entorno da área}

Após a realização do monitoramento durante cinco meses, em períodos quinzenais na MS $162 \mathrm{~km} 50$ - 80, compreendendo o trecho do Distrito de Quebra Coco à Sidrolândia, MS, foram obtidos os seguintes resultados. Foram encontrados 18 animais divididos em nove espécies.

No primeiro dia de monitoramento, foram encontrados quatro indivíduos, sendo todos tamanduás, um tamanduá mirim Tamandua tetradactyla localizado no km 68 e três tamanduás bandeira Myrmecophaga tridactyla localizados nos km 62 e 51. Nesse primeiro dia de monitoramento, houve um caso de atropelamento duplo, envolvendo mãe e filhote km (51). No segundo dia, registrou-se o atropelamento de um indivíduo, sendo tamanduá bandeira (Figura 4), encontrado no km 61. No terceiro dia de monitoramento, encontraram-se três indivíduos atropelados, sendo um tamanduá bandeira no km 55, uma serpente Hydrodynastes gigas no km 53, e um papagaio Amazona aestiva também no km 53.

No quarto dia, encontrou-se um único indivíduo tamanduá bandeira, localizado no km 67. No quinto dia de monitoramento, também se registrou um indivíduo tamanduá mirim no km 69. No sexto dia, encontraram-se três indivíduos atropelados sendo um tamanduá bandeira no km 71, um furão Galictis vittata no km 67 e um tatu peba Euphractus sexcenctus no km 64. No sétimo dia de monitoramento, não houve o registro de nenhum animal atropelado. No oitavo dia de monitoramento, foram encontrados três indivíduos novamente, sendo um anu branco Guira guira localizado no km 73, um tatu peba localizado no km 62 e um sapo cururu Rhinella icterica no km 69. No 
nono dia de pesquisa foram encontrados dois indivíduos, um jacaré de papo amarelo Caiman latirrostris (Figura 5), localizado no km 53, e um tamanduá bandeira, localizado no km 57.

No décimo e último dia de monitoramento, não houve nenhum registro de animal atropelado.

Percebeu-se, a partir dos dados coletados, que no Trecho entre os Km 51 até Km 73 houve uma incidência maior de animais atropelados. É possível que isso tenha ocorrido devido à composição da paisagem, ou seja, áreas que favorecessem mais recursos, portanto, mais condições para sobrevivência e riqueza daqueles animais. Outro fator que também pode ter influenciado é que, nesse trecho de maior incidência, a pista é uniforme e com boa visão, talvez influenciando no aumento da velocidade por parte dos condutores, ocasionando esses acidentes. Os resultados para melhor visualização estão dispostos no quadro 1.

\begin{tabular}{|c|c|c|c|c|}
\hline $\begin{array}{c}\text { No } \\
\text { Amostra }\end{array}$ & $\begin{array}{c}\text { Dia de } \\
\text { amostragem }\end{array}$ & Nome popular & Nome Científico & KM \\
\hline 1 & 1a quinz./nov & Tamanduá-mirim & Tamandua tetradactyla & 68 \\
\hline 2 & 1a quinz./nov & Tamanduá-bandeira & Myrmecophaga tridacty/a & 63 \\
\hline 3 & 1a quinz./nov & Tamanduá-bandeira & Myrmecophaga tridactyla & 51 \\
\hline 4 & 1a quinz./nov & Tamanduá-bandeira & Myrmecophaga tridacty/a & 51 \\
\hline 5 & 2a quinz./nov & Tamanduá-bandeira & Myrmecophaga tridactyla & 61 \\
\hline 6 & 1a quinz./dez & Tamanduá-bandeira & Myrmecophaga tridacty/a & 55 \\
\hline 7 & 1a quinz./dez & Serpente & Hydrodynastes gigas & 53 \\
\hline 8 & 1a quinz./dez & Papagaio verdadeiro & Amazona aestiva & 53 \\
\hline 9 & 2a quinz./dez & Tamanduá-bandeira & Myrmecophaga tridactyla & 67 \\
\hline 10 & 1a quinz./jan & Tamanduá-mirim & Tamandua tetradactyla & 69 \\
\hline 11 & 2a quinz./jan & Tamanduá-bandeira & Myrmecophaga tridactyla & 71 \\
\hline 12 & 2a quinz./jan & Furão & Galictis vittata & 67 \\
\hline 13 & 2a quinz./jan & Tatu-peba & Euphractus sexcenctus & 64 \\
\hline
\end{tabular}


Trilha da Vida Silvestre: um jogo a partir do monitoramento de atropelamento de animais em trecho da Rodovia MS 162

\begin{tabular}{|c|c|c|c|c|}
\hline $\begin{array}{c}\text { № } \\
\text { Amostra }\end{array}$ & $\begin{array}{c}\text { Dia de } \\
\text { amostragem }\end{array}$ & Nome popular & Nome Científico & KM \\
\hline 14 & 2a quinz./fev & Anu-Branco & Guira guira & 73 \\
\hline 15 & 2a quinz./fev & Tatu-peba & Euphractus sexcenctus & 62 \\
\hline 16 & 2a quinz./fev & Sapo cururu & Rhinella icterica & 69 \\
\hline 17 & 1a quinz./mar & Jacaré-do-papo-amarelo & Caiman latirrostris & 52 \\
\hline 18 & 1a quinz./mar & Tamanduá-bandeira & Myrmecophaga tridactyla & 57 \\
\hline
\end{tabular}

Quadro 1- Registro dos animais encontrados atropelados entre o período de novembro de 2013 a março de 2014 na Rodovia MS 162 Km 50- 80, compreendendo o trecho do Distrito de Quebra Coco à Sidrolândia, MS

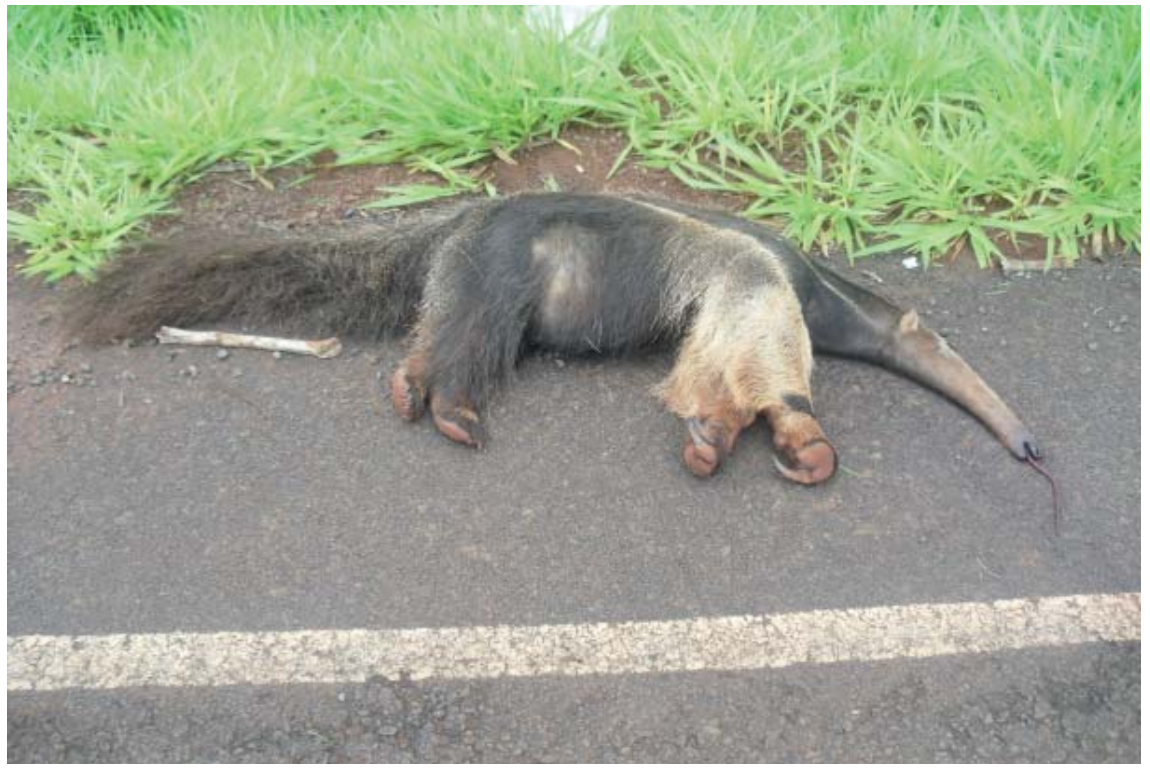

Figura 4- Tamanduá Bandeira encontrado atropelado na MS 162 


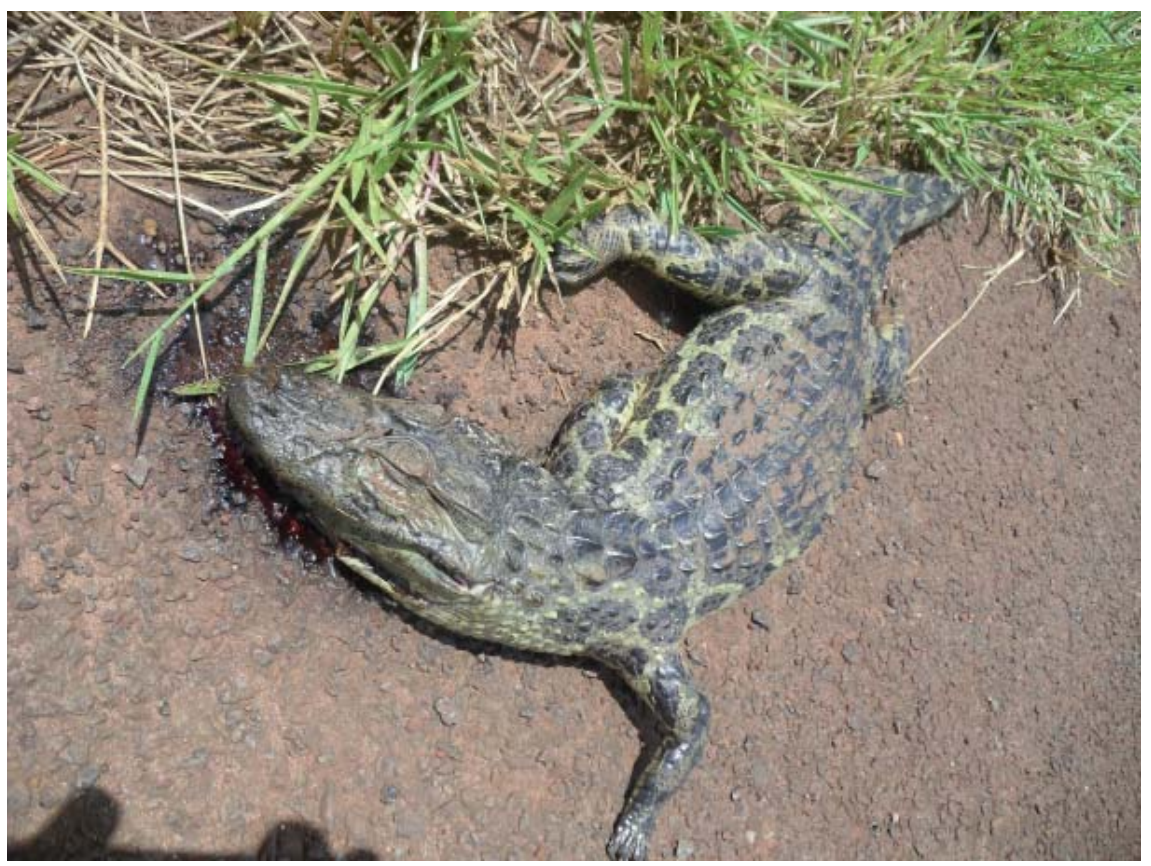

Figura 5- Jacaré do papo amarelo encontrado na MS 162 atropelado

\subsection{Jogo didático}

Com base na pesquisa de campo, produziu-se um jogo didático de trilha destinado a alunos do ensino fundamental, anos iniciais. 0 jogo de tabuleiro compreende os $31 \mathrm{~km}$ de pista, representados por 62 casas, sendo duas casas por km. A pista é ilustrada pelas cores do semáforo, sendo elas: vermelho, verde e amarelo. As casas contêm informações para seguir no jogo, são elas: penalidades, bônus e mensagens de advertência e conscientização. O jogador deve seguir pela trilha com bastante atenção e chegar ao final do jogo de acordo com as regras estabelecidas. 


\section{DISCUSSÃO}

Conforme os resultados obtidos na pesquisa, encontraram-se 18 indivíduos de nove espécies diferentes. Dentre as espécies encontradas, apenas três obtiveram mais de um indivíduo atropelado, sendo eles: tatu peba, tamanduá mirim e bandeira. Dos animais como o jacaré, o anu, o sapo cururu, o papagaio, o furão e a serpente, foi encontrado um único indivíduo atropelado por espécie.

A espécie que obteve maior ocorrência foi a de tamanduá bandeira, sendo oito indivíduos da espécie. Esse fato pode estar relacionado com a maior abrangência desses indivíduos na área, com o nicho que ocupam, o comportamento desses animais e o seu porte.

$\mathrm{O}$ andar lento desses animais pode ser um fator que contribua para o alto índice de atropelamento encontrado. No estudo de Medri (2002), encontraram-se 12 tamanduás durante o período de março a setembro de 2001, dos quais nove eram machos, e três eram fêmeas. $\mathrm{O}$ porte das fêmeas variou de 37 e $46 \mathrm{~kg}$ entre as de porte adulto e de $24 \mathrm{~kg}$ aquelas de porte sub-adulto. Já os machos variaram de 31 a $39 \mathrm{~kg}$, todos aparentemente adultos. O estudo também mostrou que embora da mesma espécie-Myrmecophaga tridactyla - houve animais que se utilizavam de fitofisionomias diferentes.

Fischer (1997), em seu estudo de monitoramento na BR 262-rodovia Campo Grande-Corumbá, encontrou grande número e variedades de espécies atropeladas. Das 84 espécies identificadas, 27 eram de mamíferos (32,1\%), 31 espécies de aves (36,9\%), e 26 representantes da herpetofauna (31\%), sendo quatro espécies de anfíbios e 22 de répteis. Durante essa pesquisa somente em dois meses, isolados entre si, não houve registro de alguma espécie nova na amostragem. Os mamíferos representaram $67,2 \%$ dos registros, aves $19,4 \%$, répteis $12,6 \%$ e anfíbios $0,8 \%$. A espécie de mamífero mais comum foi o cachorro-do-mato (Cerdocyon thous), seguida da capivara (Hydrochaeris hydrochaeris), 
tamanduás (Myrmecophaga trydactila e Tamandua tetradactila) e tatus (Dasypus novemcinctus e Euphractus sexcinctus).

Estudos foram realizados na BR 262, trecho de Campo Grande, Aquidauana e Miranda. Ao todo foram feitas 50 viagens de Campo Grande a Aquidauana e 30 viagens de Aquidauana a Miranda. Durante o período de pesquisa, registraram-se com maior frequência as seguintes ordens: Carnivora (91 registros), Cingulata (73 registros) e Pilosa (55 registros). Os animais mais atropelados foram o lobinho (Cerdocyon thous) com 71 registros, o tatu-peba (Euphractus sexcinctus) com 52, o tamanduá-bandeira (Myrmecophaga tridactyla) com 36, o tatu-galinha (Dasypus novemcinctus) com 20 e o tamanduá-mirim (Tamandua tetradactyla) com 19 registros. Em relação à distribuição espacial de atropelamentos, houve tendência de formação de agrupamentos para todas as escalas analisadas, não havendo nítida distinção entre os períodos seco e chuvoso (CASELLA, 2010).

Como visto acima, muitos estudos apontam registros de mamíferos, répteis e aves atropelados, fato também observado neste estudo. Os tamanduás estão presentes em quase todos os estudos de monitoramento de fauna realizados e apresentam grande predomínio nas áreas de Cerrado e grande taxa de atropelamento. O presente estudo também registrou grande predominância destes, sendo um total de oito indivíduos da espécie Myrmecophaga tridactyla e 2 da espécie Tamandua tetradactyla. Os locais onde ocorreu maior incidência de atropelamento de animais compreende entre os quilômetros 51 a 57, sendo registrado sete animais, e entre os quilômetros 63 e 73, sendo 11 animais atropelados, fator que pode estar relacionado com as características do trajeto, pois, em locais com curvas e próximos à área de habitação (a partir do km 75), a incidência foi menor ou nula.

A diversidade biológica cada vez mais vem sendo reconhecida como elemento fundamental para equilíbrio e bem-estar da humanidade, reconhecendo sua importância e papel no equilíbrio ambiental 
global (FERRO et al., 2006). Atualmente, no entanto, as florestas vêm sendo significativamente fragmentadas, muitas vezes separadas por áreas de plantação agrícola (principalmente de soja, milho e feijão), pastagens e plantações de Pinus (CHEREM, 2007).

A introdução de estradas que cruzam áreas naturais configura-se como um dos primeiros passos para o início do processo de alteração de ambientes. Independentemente do incentivo à ocupação humana ou não, a presença da rodovia pode trazer "novidades" ambientais para a região. As estradas são utilizadas pelo homem desde tempos remotos, portanto, ou se encara a nossa interação com o natural positivamente, ou continua-se com a ideia de que se deve isolar homem e natureza (FISCHER, 1997).

As estradas podem interferir de diversas maneiras e gerar grandes efeitos ecológicos, dentre eles, a destruição do habitat no entorno da rodovia, que se configura como uma das causas geradoras de mudança no comportamento de espécies e o atropelamento de fauna (INSTITUTO BRASÍLIA AMBIENTAL [IBRAM], 2014). Ao mesmo tempo em que gera desenvolvimento e progresso, a construção de estradas gera grandes e diversos impactos ambientais. Em alguns países, esses fatores já atingiram elevados índices de mortalidade de animais, superando os danos causados pela caça (VIEIRA et al., 2012).

A construção de estradas afeta a fauna devido a alterações que causam no comportamento animal e pelas modificações nas movimentações padrões que esses animais realizam (SANTANA, 2012). No Brasil, estudos focando o impacto de rodovias em animais selvagens têm sido feitos em diversas regiões, mas tipicamente têm se limitado a quantificar o número de atropelamentos e listar as espécies mortas ao longo de rodovias (CATELLA, 2010).

Os atropelamentos, segundo Lima e Obara (2004), ocorrem em função de dois aspectos principais, sendo o primeiro o fato de a rodovia cortar o habitat de determinado taxon, interferindo na faixa de deslo- 
camento natural da espécie, o mesmo acontecendo para uma rodovia estabelecida em área de migração; e o segundo, a disponibilidade de alimentos ao longo das rodovias, que serve de atrativo para fauna.

Quando uma estrada subdivide uma paisagem natural, removendo uma porção de habitat, acaba ocasionando vários distúrbios, tais como alteração da migração das espécies naturais além de facilitar a propagação de incêndios, caça, entre outros (SCOSS, 2002).

O número de animais mortos nas rodovias do Brasil aumenta gradativamente a cada ano, e esse fato agrava-se principalmente em rodovias onde o fluxo de automóveis é mais intenso e que cortam áreas com grande riqueza de animais e plantas (CASELLA, 2006).

O impacto das estradas inicia-se na fase de construção, em que ocorre a perda e alteração de habitat. Quando construídas, o impacto vem do choque de animais com os automóveis (REZINI, 2010).

De acordo com dados do Instituto Brasília Ambiental, o atropelamento de animais é reconhecido como a principal causa direta de mortalidade de animais vertebrados, superando outros impactos. Nos Estados Unidos, por exemplo, foram estimados 365 milhões de atropelamentos/ano (década de 60), na Espanha 100 milhões (década de 90) e na Alemanha 32 milhões (1987-1988). Segundo o Centro Brasileiro de Estudos de Ecologia de Estradas (CBEE), a estimativa é de que mais de 15 animais morrem nas estradas brasileiras a cada segundo. Diariamente devem morrer mais de 1,3 milhões de animais. E, ao final de um ano, mais de 475 milhões de animais selvagens são atropelados no Brasil (IBRAM, 2014).

De acordo com o estudo de Cherem (2007), um número significativo de espécies de mamíferos de médio e grande porte foi registrado nas rodovias de Santa Catarina.

Diante desses acontecimentos, algumas medidas podem ser tomadas para a minimização desses efeitos, tais como construção de túneis, priorização de trechos, cercas e outros aparatos. Para tanto, a 
priorização de trechos para a implantação dessas ações de minimização de atropelamentos deve ser realizada com cautela para que áreas importantes não sejam eliminadas durante um processo de seleção (BAGER et al., 2009). A implementação de dutos ou passagens para animais silvestres estão sendo utilizados na tentativa de facilitar de forma segura a travessia desses animais. No entanto a literatura tem mostrado que nem sempre estes artefatos surtem os efeitos desejados, isso se deve ao fato de que muitas espécies não atravessam lugares estreitos e fechados, além disso, esses lugares podem tornar-se verdadeiras armadilhas e colocar a vida do animal em risco (CATELLA, 2010).

Scoss (2002) também diz que, no caso da implantação de estruturas artificiais, alguns aspectos devem ser considerados antes da tomada de decisão.

A vegetação cada vez mais fragmentada e degradada se deve em grande parte à abertura de estradas e da ocupação de novas áreas no Domínio da Floresta Atlântica, e exige estudos e necessariamente ações que visem à recuperação das áreas já alteradas, e propostas que minimizem os efeitos negativos nas áreas da fragmentação florestal (SCOSS, 2002).

De acordo com o Departamento Nacional de Infraestrutura de Transporte (DNIT), a inserção de medidas para proteção de fauna silvestre dos atropelamentos em rodovias é ainda muito recente no Brasil. Os projetos e obras em rodovias que estão sendo implementadas sob responsabilidade do DNIT vêm obedecendo às diretrizes de soluções de proteção à fauna, em linha com as orientações dos órgãos ambientais (DNIT, 2012).

Umas das soluções e maneira encontradas para solucionar ou amenizar a grande perda de biodiversidade é a educação ambiental. A partir dos anos 80, a educação ambiental tornou-se objeto cada vez mais estudado por parte de educadores e ambientalistas brasileiros (RIBEIRO; RAMOS, 1999). 
A educação ambiental vem ganhando cada vez mais destaque e avançando, mas, apesar dos avanços, existem muitas maneiras de pensar a educação relacionada à problemática ambiental, múltiplas formas de agir e, por consequência, inúmeros problemas (RIBEIRO; RAMOS, 1999).

Refletir sobre as práticas sociais, em um contexto marcado pela degradação permanente do meio ambiente e do seu ecossistema, envolve uma necessária articulação com a produção de sentidos sobre a educação ambiental. A questão ambiental configura-se crescentemente como uma questão que envolve cada vez mais atores do universo educativo, envolvendo a importância e engajamento dos diversos sistemas de conhecimento, a capacitação de profissionais e a comunidade universitária numa perspectiva interdisciplinar (JACOBI, 2003).

Tendo como referência o fato de que a maior parte da população brasileira vive em cidades, observa-se uma crescente degradação das condições de vida, refletindo uma crise ambiental. A preocupação com o desenvolvimento sustentável representa a possibilidade de garantias de mudanças sociopolíticas que não comprometam os sistemas ecológicos e sociais que sustentam as comunidades (JACOBI, 2003).

\section{CONSIDERAÇÕES}

Com o presente trabalho, pode-se conhecer melhor a gravidade dos atropelamentos de animais silvestres para a biodiversidade local e produzir um jogo didático de trilha com dados reais. A perda da biodiversidade é um fator recorrente e que contribui para declínios ambientais, gerando danos não somente para os indivíduos da espécie em questão, mas sim para todos aqueles que se inter-relacionam com esta, de uma maneira ou de outra. A perda de biodiversidade é um assunto que deve ser debatido e, cada vez mais, merece atenção e esforços na busca de alternativas para sua conservação e preserva- 
Trilha da Vida Silvestre: um jogo a partir do monitoramento de atropelamento de animais em trecho da Rodovia MS 162

ção. Espera-se que o jogo "Trilha da Vida Silvestre" possa auxiliar na sensibilização de alunos dos anos finais do ensino fundamental para possíveis trabalhos de educação ambiental.

\section{REFERÊNCIAS}

BAGER, A. et al. Hierarquização de quilômetros prioritários a implantação de aparatos de mitigação de atropelamentos de animais selvagens- estudo de caso da BR 392. In: CONGRESSO DE ECOLOGIA DO BRASIL, 9., 13 a 17 de setembro de 2009. Anais... São Lourenço, MG, 2009.

CASELLA, J. et al. Uso de sensoriamento remoto e análise espacial na interpretação de atropelamentos de fauna entre Campo Grande e Aquidauana, MS. In: SIMPÓSIO DE GEOTECNOLOGIAS NO PANTANAL, 1. Anais... Campo Grande, MS: Embrapa Informática Agropecuária/INPE, 2006. p.321-326.

CASELLA, J. Ecologia de estradas: influência da BR-262 no desflorestamento e na perda da fauna silvestre por atropelamentos no Sudoeste do Brasil, MS. 2010. 105 f. Tese (Doutorado Ecologia e Conservação) - Universidade Federal do Mato Grosso do Sul, Campo Grande, MS, 2010.

CATELLA, A. C. et al. BR-262 no Pantanal: cenário de encontros entre homens e animais silvestres. Corumbá, MS: Embrapa Pantanal, 2010.

CHEREM, J. J. et al. Mamíferos de médio e grande porte atropelados em rodovias do Estado de Santa Catarina, sul do Brasil. Revista Biotemas, v. 20, n. 3, p. 81-96, set. 2007.

DEPARTAMENTO NACIONAL DE INFRAESTRUTURA DE TRANSPORTES (DNIT). Monitoramento e mitigação de atropelamento de fauna. Brasília: Coordenação Geral de Meio Ambiente/Diretoria de Planejamento e Pesquisa, 2012. (Coleção Estrada Verde, v. 1/3).

FERRO, A. F. P. et al. Oportunidades tecnológicas e estratégias concorrenciais de gestão ambiental: o uso sustentável da biodiversidade brasileira. Produção e Gestão, Campinas, SP, v. 13, n. 3, p. 489-501, 2006.

FISCHER, W. A. Efeitos da rodovia BR-262 na mortalidade de vertebrados silvestres: síntese naturalística para a conservação da região do Pantanal, MS. 1997. 42 f. Dissertação (Mestrado em Ecologia e Conservação) - Universidade Federal do Mato Grosso do Sul, Campo Grande, MS, 1997. 
INSTITUTO BRASÍLIA AMBIENTAL (IBRAM). RODOFAUNA - Monitoramento de Fauna Silvestre Atropelada. Brasília, 2014. Disponível em: <http://www. ibram.df.gov.br/component/content/article/261.html>.

JACOBI, P. Educação ambiental, cidadania e sustentabilidade. Cadernos de Pesquisa, n. 118, p, 189-205, mar. 2003.

LIMA, S. F.; OBARA, A. T. Levantamento de animais silvestres atropelados na BR-277 às margens do Parque Nacional do Iguaçu: subsídios ao programa multidisciplinar de proteção à fauna. In: SEMANA DE ARTES DA UNIVERSIDADE ESTADUAL DE MARINGÁ, 7. Anais... Maringá, PR: UEM, 2004.

MEDRI, I. M. Área de vida e uso de habitát de Tamanduá - bandeira Myrmecophaga tridactyla Linnaeus, 1758- nas fazendas Nhumirim e Porto Alegre, Pantanal de Nhecolândia, MS. 2002. 71 f. Dissertação (Mestrado em Ecologia e Conservação) - Universidade Federal de Mato Grosso do Sul, Campo Grande, MS, 2002.

REZINI, J. A. Atropelamento de mamíferos e rodovias do leste dos estados do Paraná e Santa Catarina, sul do Brasil. 2010. 60 f. Dissertação (Mestrado em Ecologia e Conservação) - Universidade Federal do Paraná, Curitiba, PR, 2010.

PATRIARCHA-GRACIOLLI, S. R. et al. "Jogo dos predadores": uma proposta lúdica para favorecer a Aprendizagem em ensino de ciências e educação ambiental. REMEA - Revista Eletrônica Mestrado Educação Ambiental, v. 20, jan./jun. 2008.

RIBEIRO, M. R. C; RAMOS, F. A. G. Educação ambiental no cotidiano escolar: estudo de caso etnográfico. Cadernos de Pesquisa, São Luiz, MA, v. 10, n. 2, p. 9-21, jul./dez. 1999.

SANTANA, G. S. Fatores influentes sobre atropelamentos de vertebrados na região central do Rio Grande do Sul, Brasil. Neotropical Biology and Conservation, Santa Maria, RS, v. 7, n. 1, p. 26-40, 2012.

SCOSS, L. M. Impacto de estradas sobre mamíferos terrestres: o caso do parque estadual do rio doce, Minas Gerais. 2002. 96 f. Tese (Doutorado em Ciência Florestal) - Universidade Federal de Viçosa, Viçosa, MG, 2002.

VIEIRA, Heider Damas et al. Resultados preliminares do subprograma de controle de atropelamento de fauna BR-060. In: CONGRESSO BRASILEIRO DE GESTÃO AMBIENTAL, 3. Goiânia, GO: IBEAS - Instituto Brasileiro de Estudos Ambientais, 2012. Disponível em: <http://www.ibeas.org.br/congresso/ Trabalhos2012/XI-031.pdf>. 